\title{
Antigen-induced Pleural Eosinophilia is Suppressed in Diabetic Rats: Role of Corticosteroid Hormones
}

\author{
Bruno L Diaz, Magda F Serra, Emiliano O Barreto, Renato SB Cordeiro, \\ Marco A Martins, Patricia MR e Silva ${ }^{+}$
}

Laboratório de Inflamação, Departamento de Fisiologia e Farmacodinâmica, Instituto Oswaldo Cruz, Av. Brasil 4365, 21045-900 Rio de Janeiro, RJ, Brasil

Previous studies have evidenced for the existence of interactive regulatory mechanisms between insulin and steroid hormones in different systems. In this study, we have investigated whether endogenous corticosteroids could be implicated in the hyporeactivity to antigen challenge observed in sensitized diabetic rats. Alloxinated rats showed a long-lasting increase in the blood glucose levels and a reduction in the number of pleural mast cells at 48 and $72 \mathrm{hr}$, but not at $24 \mathrm{hr}$ after alloxan administration. In parallel, they also showed a significant elevation in the plasma levels of corticosterone together with an increase in the adrenal/body weight ratio. Antigen-evoked eosinophil accumulation appeared significantly reduced in rats pretreated with dexamethasone as well as in those rendered diabetic $72 \mathrm{hr}$ after alloxan. In the same way, naive animals treated with dexamethasone also responded with a significant decrease in the number of pleural mast cells. Interestingly, when sensitized diabetic rats were pretreated with the steroid antagonist $R U 38486$ a reversion of the reduction in the allergen-induced eosinophil accumulation was noted. We conclude that the down-regulation of the allergic inflammatory response in diabetic rats is close-related to reduction in mast cell numbers and over expression of endogenous corticosteroids.

Key words: diabetes - allergic pleurisy - mast cells - eosinophils - corticosteroids

Diabetes is a metabolic disorder in which there is an impairment of glucose utilization caused by a derangement in insulin function. Thus, hyperglycemia concomitant with other metabolic disfunctions as peripheral insulin resistance are characteristic features of this disease (WHO Study Group 1985). Studies in experimental animals and investigations in diabetic individuals demonstrated their fail in mounting a properly inflammatory reaction, though the precise mechanism underlying this phenomenon is still unknown. There are some pieces of evidence demonstrating that diabetics show alterations in the microcirculatory reactivity as well as functional abnormalities in leucocyte functions (Llorach et al. 1976, Pereira et al. 1987). Previous studies reported that diabetics may show hypertrophy of the adrenal cortex concomitant with an increase in the adrenal steroid production (Kraus

\footnotetext{
This study was supported by grants from Conselho Nacional de Desenvolvimento Científico e Tecnológico (CNPq) and Fundação de Amparo à Pesquisa do Estado do Rio de Janeiro (FAPERJ), Brazil.

${ }^{+}$Corresponding author. Fax: +55-21-590.9490. E.mail: patmar@gene.dbbm.fiocruz.br

Received 3 September 1997

Accepted 30 September 1997
}

1973). Glucocorticoids have long been known as powerful anti-inflammatory compounds which have an important modulatory effect on different cell types including mast cells and eosinophils (reviewed in Schleimer 1990). In a variety of species, treatment with glucocorticoid effectively prevented infiltration of eosinophils into local tissue sites after antigen stimulation (Sanjar et al. 1990, Sullivan et al. 1994). We have recently reported that rats with alloxan diabetes show a reduction in the pleural mast cell population and also a suppression of the antigen-induced pleural eosinophilia, phenomena clearly sensitive to insulin treatment (Diaz et al. 1996). The purpose of this study was to investigate the relationship between endogenous corticosteroids and the pleural mastocytopenia as well as the hyporeactivity to antigen challenge in alloxan diabetic rats.

\section{MATERIALS AND METHODS}

Male Wistar rats from the Oswaldo Cruz Foundation breeding were used and diabetes was induced by a single injection of alloxan monohydrate (Sigma St. Louis, USA) (40 mg/kg, i.v.;) into 12 $\mathrm{hr}$ fasted rats. Control animals were injected with vehicle and submitted to similar experimental conditions. In another set of experiments, alloxan was injected 24,48 or $72 \mathrm{hr}$ before antigen challenge 
in sensitized rats. Glucose concentration was determined spectrophotometrically in whole blood and only rats with glucose levels above $200 \mathrm{mg} / \mathrm{dl}$ were considered in further experiments. Active sensitization was performed subcutaneously with ovalbumin (OVA; Fluka Chemie AG, Switzerland) $(50 \mu \mathrm{g})$ and $\mathrm{Al}(\mathrm{OH})_{3}(5 \mathrm{mg})$ and 14 days later, the animals were challenged with an intrapleural (i.pl.) injection of OVA (12 $\mu \mathrm{g} /$ cavity). Pleurisy was evaluated as previously described (Silva et al. 1992). Total and differential leucocyte counts were performed in an automatic cell counter and in cytospin preparations stained with May-GrunwaldGiemsa dye, respectively. Mast cells were stained with toluidine and counted in a Neubauer chamber. Plasma corticosterone levels were determined using a radioimmunoassay (ICN Pharmaceuticals), and both adrenal glands were dried for $24 \mathrm{hr}$ at $40^{\circ} \mathrm{C}$ and weighed. Dexamethasone (Prodrome, Brazil) was administered either $1 \mathrm{hr}$ before antigen $(0.5 \mathrm{mg} / \mathrm{kg})$ or once a day during three days $(0.1 \mathrm{mg} / \mathrm{kg})$ in the case of naive rats. The steroid antagonist RU38486 (11ß-(4-dimethyl aminophenyl)17ß-hydroxy, $17 \alpha$ (prop-1-ynyl) estra 4,9dien-3-one; a kind gift from Roussel-Uclaf, Romainville, France) was administered orally (20 $\mathrm{mg} / \mathrm{kg}$ ) $2 \mathrm{hr}$ before the alloxan injection and twice a day during two days following diabetes induction. The data were statistically analyzed by ANOVA followed by the Newman-Keuls-Student's $t$ test and values of 0.05 or less considered significant.

\section{RESULTS}

We observed that intravenous administration of alloxan $(40 \mathrm{mg} / \mathrm{kg})$ into rats led to a progressive increase in the blood glucose concentration, maximal at three days (Fig. 1A). In parallel, a selective reduction in the number of mast cells recovered from the pleural cavity was noted at 48 and $72 \mathrm{hr}$, but not at $24 \mathrm{hr}$ after alloxan, lasting for at least 60 days (Fig. 1A). Alloxinated rats also showed an elevation in the plasma corticosterone levels (Fig. 1B) as well as in the ratio of combined adrenal glands/body weight at $72 \mathrm{hr}$ after diabetes induction. Ratio values were $0.043 \pm 0.004$ (mean \pm SEM) $(n=6)$ in controls and $0.104 \pm 0.008$ in diabetic animals $(n=7)(\mathrm{p}<0.001)$. Experiments were further performed to evaluate whether the reduction in the pleural mast cell population noted in diabetic rats might influence the antigen-induced eosinophilia. As illustrated in Fig. 2, sensitized rats rendered diabetic 48 and $72 \mathrm{hr}$ but not $24 \mathrm{hr}$ before, showed a less pronounced eosinophil accumulation when compared to sensitized non-diabetics. In addition, we verified that treatment of sensitized rats with dexamethasone $(0.5 \mathrm{mg} / \mathrm{kg}$, i.p. $) 1 \mathrm{hr}$ before the ovalbumin, markedly inhibited the eosinophilia noted $24 \mathrm{hr}$-post challenge. The number of eosinophils decreased from $16.74 \pm 2.47 \times 10^{6}$ cells/cavity (mean \pm SEM) $(n=8)$ in controls to $2.07 \pm 0.35 \times 10^{6}$ cells/cavity in treated animals $(\mathrm{n}=8)(\mathrm{p}<0.001)$. When dexamethasone $(0.1 \mathrm{mg} /$ $\mathrm{kg}$ ) was administered into naive rats once a day, during three days, a significant reduction in the number of pleural mast cells was noted, values decreasing from $583.8 \pm 27.9 \times 10^{3}$ cells/cavity $($ mean \pm SEM $)(n=8)$ in controls to $311.3 \pm 24.8 x$ $10^{3}$ cells/cavity $(\mathrm{n}=8)(\mathrm{p}<0.001)$ in treated rats. The involvement of endogenous corticosterone in the hyporeactivity to allergen challenge in diabetics was further investigated by treating the animals with the steroid antagonist compound RU38486. Sensitized diabetic rats treated with RU38486 (20 $\mathrm{mg} / \mathrm{kg}$ ) showed a significant reversion of the decrease in the allergen-induced eosinophil accumulation (Fig. 3).
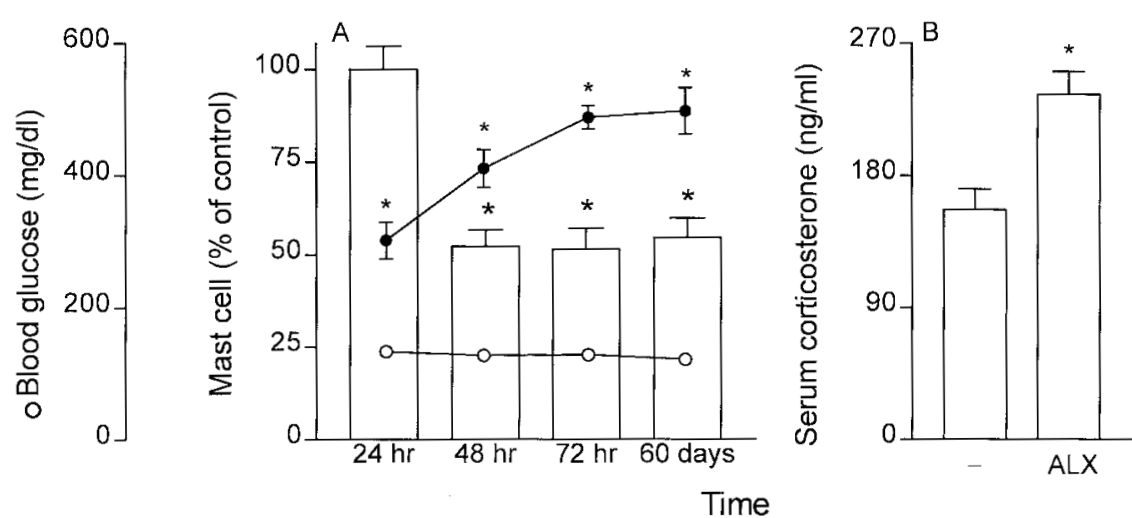

Fig. 1 - (A): kinetics of alteration in the blood glucose levels and in the number of pleural mast cells following alloxan injection (40 $\mathrm{mg} / \mathrm{kg}$, i.v.) into naive rats. (B) Plasma corticosterone levels in $72 \mathrm{hr}$-diabetic rats. Bars represent means \pm SEM from at least seven animals. ${ }^{*} \mathrm{p}<0.05$ as compared to untreated rats (controls). 


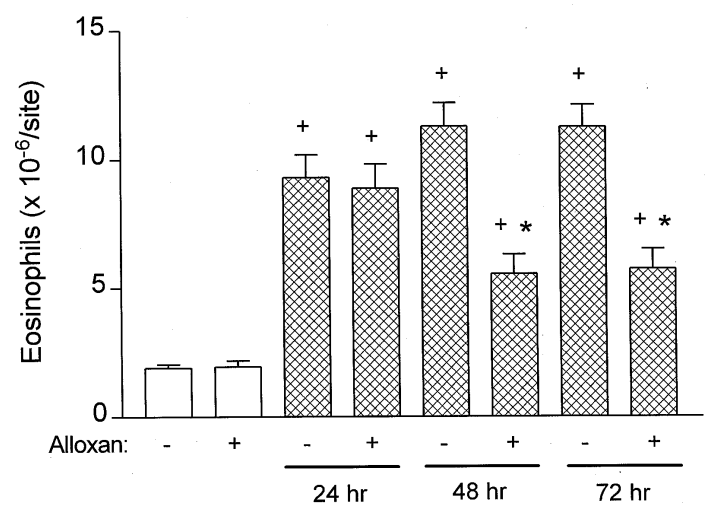

Fig. 2: influence of diabetes on antigen-induced pleural eosinophil influx in sensitized rats. Sensitized rats (cross-hatched columns) were injected with alloxan ( $40 \mathrm{mg} / \mathrm{kg}$ ) 24, 48 and 72 $\mathrm{hr}$ before challenge (ovalbumin, $12 \mu \mathrm{g} /$ cavity), and eosinophil infiltration evaluated $24 \mathrm{hr}$ after challenge. Non-sensitized animals (opened columns) injected with OVA were used as controls. Data are expressed as means \pm SEM from at least seven animals. $* \mathrm{p}<0.05$ as compared to untreated rats; $+\mathrm{p}<0.05$ as compared to non-sensitized rats.

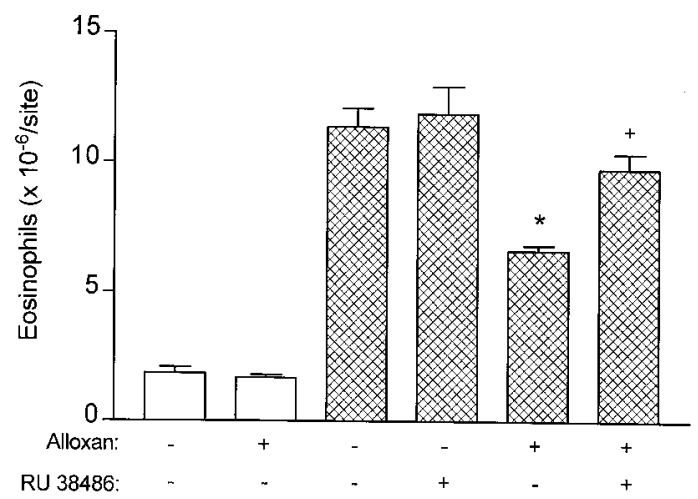

Fig. 3: oral treatment with the steroid receptor antagonist RU $38486(20 \mathrm{mg} / \mathrm{kg})$ reversed the reduction of allergen-induced eosinophil recruitment noted in alloxan-treated rats. Sensitized animals (cross-hatched columns) were injected with alloxan (40 $\mathrm{mg} / \mathrm{kg}) 72 \mathrm{hr}$ before OVA (12 $\mu \mathrm{g} /$ cavity), and eosinophil infiltration evaluated $24 \mathrm{hr}$ after challenge. Non-sensitized animals (opened columns) injected with OVA were used as controls. Data are expressed as means \pm SEM from at least seven animals. $*$ p $<0.05$ as compared to sensitized untreated rats; $+\mathrm{p}<0.05$ as compared to non-sensitized rats.

\section{DISCUSSION}

Diabetics hardly exhibit typical inflammatory reaction, a phenomenon associated with the development of the diabetic state, but independent of alterations in the peripheral blood leucocytes and cellular glucopenia. In this study, we demonstrated that rats rendered diabetic after alloxan administration showed a significant increase in the blood glucose levels already detected $24 \mathrm{hr}$ after alloxan, and also that the eosinophil accumulation triggered by antigen in the rat pleural cavity was clearly suppressed in the 48- and 72-hr but not $24 \mathrm{hr}$-diabetic animals. Our data are in accordance with a previous study which demonstrated the reduction in the number of eosinophils in the bronchoalveolar lavage recovered from sensitized diabetic rats (Vianna $\&$ Garcia-Leme 1995). It is noteworthy that the chemotactic response of diabetic eosinophils to PAF or $\mathrm{LTB}_{4}$ in vitro did not differ from that of normal eosinophils (data not shown), indicating the absence of an intrinsic abnormality in the locomotory function of these cells. Interestingly, in parallel to the above mentioned diabetes alterations, alloxinated rats also showed a selective reduction in the number of pleural mast cells, first noted within $48 \mathrm{hr}$ and lasting for at least 60 days. Similarly, Casacó et al. (1990) demonstrated that alloxan-treated rats showed a reduction in the number of mast cells in peritoneal cavity and a clear resistance to the lethal effect of the compound 48/ 80 . We have also verified a close relationship between the time course of the reduction in the number of mast cells and the subsequent refractoriness to antigen-induced eosinophil accumulation, which was noted in rats rendered diabetics 48 and $72 \mathrm{hr}$ but not $24 \mathrm{hr}$ before. These data are consistent with the interpretation that alterations in the mast cell population may contribute to the hyporeactivity associated with diabetic state.

Though the relationship between glucocorticoids and diabetes has not been completely elucidated, it has been proposed that in the diabetes the regulation of factors controlling adrenal steroid secretion and metabolism may be altered (Wexler \& Lutmer 1975, Meehan et al. 1986). We have found that $72 \mathrm{hr}$-alloxinated rats showed higher levels of plasma corticosterone and an increase in the adrenal gland/body weight ratio, confirming previous reports (Lentle \& Thomas 1964, Wexler \& Lutmer 1975, Cameron et al. 1987, Fitzpatrick et al. 1992). These alterations in diabetes may probably be dependent on changes in the steroid feedback controlling mechanisms in the hypothalamicpituitary-adrenocortical system. Glucocorticoids have been demonstrated to induce significant reduction in the number as well as in the secretory response of mast cells (Sim et al. 1992). Thus, we have further evaluated the effect of exogenous steroids on the eosinophil accumulation noted after antigen. Pretreatment with dexamethasone suppressed the allergic pleural eosinophilia and was also effective in diminishing the pleural mast cell population in naive rats. Exposure of eosinophils to dexamethasone did not affect their chemotactic response to $\mathrm{PAF}$ and $\mathrm{LTB}_{4}$ in vitro (not shown), suggesting that the glucocorticoids may be acting on an intermediate step of eosinophil recruitment, 
probably blocking the synthesis and/ or secretion of chemoattractants. Alternatively, glucocorticoids may be acting in the post-capillary venules to impair cell extravazation. Besides testing the effect of dexamethasone, we have also evaluated the involvement of endogenous corticosteroids in hyporeactivity to allergen challenge associated with diabetic state. The oral treatment of sensitized diabetic rats with the steroid receptor antagonist RU38486 (or mifepristone) reversed the reduced eosinophil accumulation, indicating a role for glucocorticoids in this phenomenon. We have reported that insulin treatment was able to reverse the suppression of allergic eosinophilia in diabetic rats (Diaz et al. 1996). Thus, considering that glucocorticoids and insulin have opposing biological effects in several systems (Garcia-Leme \& Farsky 1993), it is valid to speculate that the balance between systemic levels of these hormones may be important to determine the intensity of allergic eosinophilic response.

In conclusion, we demonstrate that the reduction in the antigen-induced eosinophil accumulation noted in alloxan diabetic rats shows a closerelationship with the decrease in the mast cell population and the augmentation in the levels of endogenous corticosteroids.

\section{ACKNOWLEDGMENTS}

To Mr Edson Alvarenga for his technical assistance.

\section{REFERENCES}

Cameron OG, Thomas B, Tiongco D, Hariharan M, Greden JF 1987. Hypercortisolism in diabetes mellitus. Diabetes Care 10: 662-664.

Casacó A, Carvajal D, Tolón Z 1991. Diabetes-induced rat hyposensitivity to compound 48/80. Can J Physiol Pharmacol 69: 886-888.

Diaz BL, Serra MF, Alves AC, Pires ALA, Corrêa FMA, Cordeiro RSB, Martins MA, e Silva PMR 1996. Alloxan diabetes reduces pleural mast cell numbers and the subsequent eosinophil influx induced by allergen in sentized rats. Int Arch Allergy Immunol 111: 36-43.

Fitzpatrick F, Christeff N, Durant S, Dardenne M, Nunez EA, Delarche FH 1992. Glucocorticoids in the nonobese diabetic (NOD) mouse: basal serum levels, effect of endocrine manipulation and immobili- zation stress. Life Science 50: 1063-1069.

Garcia-Leme J, Farsky SP 1993. Hormonal control of inflammatory responses. Mediators of inflammation 2: 181-198.

Kraus SD 1973. Adrenal and plasma corticosterone and pituitary and plasma ACTH in alloxan diabetic rats. Proc Soc Exp Biol Med 143: 460-464.

Lentle BC, Thomas JP 1964. Adrenal function and the complications of diabetes mellitus. The Lancet 2: 544-549.

Llorach MA, Bohm GM, Garcia-Leme J 1976. Decreased vascular reactions to permeability factors in experimental diabetes. Br J Exp Pathol 57: 747-754.

Meehan WP, Leedom LJ, Henry JP 1988. Diabetes mellitus, adrenal function and the defeat response. Acta Physiol Scand Suppl 571: 117-28.

Pereira MAA, Sannomiya P, Garcia-Leme J 1987. Inhibition of leukocyte chemotaxis by factor in alloxaninduced diabetic rat plasma. Diabetes 36: 1307-1314.

Sanjar S, Aoki S, Kristersson A, Smith D, Morley J 1990. Antigen challenge induces pulmonary airway eosinophil accumulation and airway hyperreactivity in sensitized guinea-pigs: the effect of anti-asthma drugs. Br J Pharmacol 99: 679-686.

Schleimer RP 1990. Effects of glucocorticosteroids on inflammatory cells relevant to their therapeutic applications in asthma. Am Rev Respir Dis 141: S5969.

Silva PMR, Martins MA, Lima MCR, Alves AC, Diaz BL, Cordeiro RSB 1992. Pharmacological modulation of the late eosinophilia induced by antigen inactively sensitized rats. Int Arch Allergy Immunol 98: 355-360.

Sim TC, Hilsmeier KA, Alam R, Allen RK, Lett-Brown MA, Grant JA 1992. Effect of topical corticosteroids on the recovery of histamine releasing factors in nasal washings of patients with allergic rhinitis. Am Rev Respir Dis 145: 1316-1320.

Sullivan P, Bekir S, Jaffar Z, Page C, Jeffery P, Costello J 1994. Anti-inflammatory effects of low-dose oral theophylline in atopic asthma Lancet 343: 10061008.

Vianna ESO, Garcia-Leme J 1995. Allergen-induced airway inflammation in rats. Am J Respir Crit Med 151: 809-814.

Wexler BC, Lutmer RF 1975. Adrenal glandular lipids and circulating corticosterone in severely diabetic rats. Br J Exp Path 56: 299-306.

WHO Study Group: Diabetes mellitus 1985. Technical Report Series 727. World Health Organization, Geneva. 